ESTUDOS LINGÜÍSTICOS 


\title{
A "GEOMETRIA" DA CONSTRUÇÃO DOS SENTIDOS EM TEXTOS INFANTIS
}

\author{
Claudia Mendes Campos*
}

\section{Introdução}

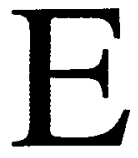

ste trabalho é o resultado de reflexões desenvolvidas a partir de um curso que ministro na graduação em Letras na Universidade Federal do

Paraná. Trata-se da discussão acerca da construção dos sentidos em textos de crianças em processo inicial ( $2^{\mathrm{a}}$ a $4^{\mathrm{a}}$ séries) de aquisição da escrita. $\mathrm{O}$ diálogo com licenciandos em Letras, ou seja, futuros professores de língua portuguesa no ensino fundamental e médio, me conduziu a uma reflexão que resvala mais na prática que na teoria - o que não significa isentar-me de discussão e filiação teórica, escolha impossível. Apenas não privilegiei, no trabalho em sala de aula, as discussões e análises teóricas, mas a identificação e avaliação daquilo que usualmente se entende por "problemas" nos textos das crianças, de forma a relacionar os sentidos construídos/reconstruídos à organização linguiística dos

* Universidade Federal do Paraná 
textos: escolhas lexicais, estruturação sintática, uso dos recursos coesivos, isto é, aos elementos lingüísticos que assegurassem, ou não, a interpretação em jogo. $O$ arcabouço teórico pressuposto na discussão do material lingüístico era o da concepção de textualidade, desenvolvida por Beaugrande \& Dressler (1980) em Introduction to text linguistics e posteriormente divulgada em trabalhos de Koch (1989,1997), Koch e Travaglia (1989,1990) e Fávero (1995).

\section{Teoria e prática}

A preocupação que me conduziu à reflexão que ora desenvolvo foi a identificação da necessidade de interferir na formação dos licenciandos em Letras não apenas através de discussões teóricas, mas também através do estabelecimento de relações explícitas entre a teoria estudada e a prática do trabalho com textos de aprendizes. Guardadas as especificidades de cada área, acredito que não seja tarefa apenas da área pedagógica trabalhar sobre questões relacionadas à prática. Em outras palavras, não acredito que as teorias sejam sempre "auto-explicáveis".

Alguém poderia questionar a validade de uma reflexão como essa, que se detém sobre textos de $2^{\mathrm{a}}$ a $4^{\mathrm{a}}$ séries, frente a alunos cuja formação não os habilitará a lecionar na primeira fase do ensino fundamental. Explico-me: entendo a aquisição da escrita como um processo, que se inicia antes mesmo de a criança entrar na escola e se estende muito além das séries iniciais. Algumas consequiências daí se seguem: as características próprias das fases iniciais não se dissolvem repentinamente, elas sofrem transformação paulatina e idiossincrática; espera-se que um aluno de qualquer das séries após a alfabetização tenha superado dificuldades iniciais como o estabelecimento da relação grafema/ fonema, mas não se supõe que tenha ele já percorrido todo o trajeto que o fará um sujeito proficiente no uso da língua escrita; no entremeio desse processo, sua produção escrita apresentará, também no que diz respeito à construção dos sentidos, tanto características próprias do início quanto do final. Vale lembrar que o processo de aquisição da linguagem, seja ela oral ou escrita, não é linear nem cumulativo, é cheio de idas e vindas, aparentes retrocessos e novos avanços (Figueira, 1996). Posso concluir então que conhecer o funcionamento de textos da fase inicial é sim saber relevante para o futuro professor de língua portuguesa do ensino médio e das últimas séries do ensino fundamental.

Por outro lado, esta reflexão, ao dirigir um olhar para textos ditos "problemáticos", em busca de sentidos construídos com as ferramentas à disposição, procurará desconstruir a imagem que estigmatiza seus produtores, isolando-os do pro- 
CAMPOS, C. M. A "Geometria" da construção...

cesso de aprendizagem e muitas vezes contribuindo inexoravelmente para a ausência de progressão na construção do conhecimento por parte desses alunos.

\section{O sentido em textos de aprendizes}

Poderia começar dizendo algo nada novo: a escola é um espaço que desestimula os sujeitos ao desenvolvimento de atividades significativas. No que diz respeito à construção dos sentidos nos textos de aprendizes, a abordagem tradicional da escola em nada se isenta da avaliação que dela se faz. Sabemos que as suas expectativas estão fundamentalmente centradas nos aspectos formais da produção textual dos alunos, tais como adequação gramatical e correção ortográfica. A construção dos sentidos e a organização textual que a sustenta são questões periféricas, se não no discurso da escola e do professor, pelo menos em relação à sua prática. Em geral o professor apresenta grande dificuldade até mesmo na deteç̧ão de eventuais contradições ou outros problemas com a coerência nos textos de seu alunado. É o que observa Charolles (1978) em um artigo no qual afirma que as intervenções feitas pelo professor nos textos dos alunos por julgá-los incoerentes fazem-se por meio de "apreciações ingênuas", pré-teóricas. O autor sugere que seriam elas "uma ativação implícita" do sistema de regras subjacente à sua avaliação textual' - no entanto, acaba por concluir que tais intervenções derivam de uma ausência de domínio acerca da gramática do texto. Ao contrário das intervenções nas frases malformadas, aquelas relativas à má formação textual não são bem explicitadas pelo professor no texto dos alunos, isto é, os professores mostram maior competência para lidar com problemas frásticos, deixando às questões textuais um tratamento periférico.

A predominância do ensino gramatical e o papel de modelo conferido ao texto na escola são também discutidos em Geraldi (1991). Segundo este autor, o texto é tradicionalmente trabalhado como "objeto de leitura vozeada, de imitação e de fixação de sentidos"; ${ }^{2}$ aluno é levado a ler em voz alta de forma o mais próximo possível da leitura do professor, a produzir textos conforme os modelos estudados e a identificar no texto o sentido pretendido pelo professor. Não é considerada a possibilidade de diferentes leituras que, mesmo imprevistas, podem ser construídas.

A tese que defendo neste artigo vai na contramão da atenção tradicionalmente dedicada ao trabalho com textos na escola. Para que este trabalho seja efe-

1 op. cit.: 46

2 op. cit.: 106 e 107 
CAMPOS, C. M. A "Geometria" da construção...

tivo, isto é, para que as aulas de língua portuguesa não girem em falso sobre seu objeto de estudo, é necessário que se instaure na sala de aula uma atividade verdadeiramente interlocutiva, o que significa dizer que é preciso que professor e alunos se constituam como interlocutores um do outro, que o espaço da aula com/ sobre textos seja o da construção de sentidos, o da busca dos caminhos que possibilitam a leitura de um texto, a (re)construção dos seus sentidos através das pistas fornecidas ${ }^{3}$. Para tanto, é preciso que tomemos o texto do aprendiz como parte de um processo de aquisição da escrita, que percebamos nele as características que lhe são próprias.

É exatamente por perceber ser plausível reconstruir sentidos em textos considerados pela escola como "problemáticos" que proponho a existência de algo que poderia chamar de "estruturação subjacente" à produção textual do aprendiz. Se ele está ainda traçando seu caminho em tal processo de construção das habilidades textuais, é incoerente procurar em seus textos as características definidoras da textualidade do escritor proficiente. Não quero com isso dizer que se deva procurar outras categorias, completamente diferentes e dissociadas daquilo que entendemos por textualidade. Quero apenas alertar para a necessidade de, dentre tais fatores, selecionar aqueles que sejam relevantes para a descrição do texto do aprendiz, ressaltando que não há como esperar rigidez em tal seleção, já que cada criança percorre o trajeto da aquisição de acordo com sua subjetividade, suas idiossincrasias. Aquilo que denominei de estruturação subjacente diz respeito às pistas deixadas pelo aprendiz através desse conjunto de características próprias ao seu texto que, associadas ao universo discursivo da criança e de seus leitores, juntamente com os fatores de coerência exiralingüísticos, permitem a reconstrução de sentidos para os textos ditos "problemáticos".

Também não quero com isso dizer que não há inadequações ou insuficiências nos textos infantis: ressalto apenas que, a despeito das intençōes da criança produtora terem ou não sido atingidas, há a possibilidade de ler seus textos e atribuir a eles sentidos - construídos a partir dos índices nele presentes, do conhecimento de mundo do leitor, de eventuais intertextualidades e das conseqüentes inferências que se façam.

3 Geraldi, op. cit. 


\section{Textualidade}

Se a expectativa é encontrar no texto infantil características próprias, porém não completamente diferentes daquelas que definem a textualidade ${ }^{4}$ do adulto proficiente, é então preciso perguntar: o que faz que um texto seja um texto?

A propriedade responsável pela constituição da textualidade é a coerên$\mathrm{cia}^{5}$. Se um material lingüístico faz sentido, ele é um texto, independentemente de seu tamanho, da modalidade em que tenha sido registrado (oral ou escrita) e inclusive independentemente de adequar-se a um padrão de língua. Pode-se dizer que a coerência não está nos textos ${ }^{6}$, mas é reconstruída pelo interlocutor, no momento da leitura, a partir de pistas deixadas pelo produtor na tentativa de construir um sentido e não outro qualquer. Portanto, como fazem parte desse jogo fatores extralingüísticos que não dependem do produtor (conhecimento de mundo, inferências, aceitabilidade), não há como garantir um único sentido. Pode haver diferentes leituras para um só texto, ele pode mesmo ser coerente para um leitor e incoerente para outro. No caso do aprendiz, ocorre que algumas vezes as pistas fornecidas são menos abundantes e menos precisas do que podem ser as de um adulto. Como observa Rocha (1999), a criança por vezes percebe dificuldades geradas em seu texto para a reconstrução pelo interlocutor dos sentidos intencionados, mas não sabe bem ainda como fazer para eliminá-las, redizendo a passagem em questão de maneira mais adequada ao que gostaria de dizer.

Para preencher as eventuais lacunas de sentidos produzem-se inferências, através da relação entre, por um lado, os elementos lingüísticos presentes no texto, representadas pelos recursos coesivos, pelas escolhas lexicais, pelas estruturas sintáticas, e, por outro, o conhecimento de mundo do leitor, o conhecimento partilhado entre interlocutores e uma possível intertextualidade. No texto do aprendiz, a inferenciação desempenha um papel fundamental. É o caso, por exemplo, de textos cuja informatividade é baixa, para os quais o leitor pode construir sentidos a partir de indices neles presentes, tais como título, elementos coesivos, escolha vocabular, registro lingüístico.

No trabalho desenvolvido por ${ }^{7}$ acerca da constituição da textualidade pela criança, o nível de informatividade revelou-se como uma categoria bastante significativa para a (re)construção dos sentidos, tanto para o leitor quanto para o produ-

4 Para uma discussão detalhada dos fatores de textualidade, ver Koch 1989 e 1990.

5 Koch, 1997; 25

6 Op. cit.

7 Rocha (op. cit. 
tor dos textos ${ }^{8}$. Sua pesquisa enfocava a interlocução entre duas crianças que conversavam sobre um texto que uma delas havia escrito e a outra havia lido. Este procedimento permitiu à autora discutir, além da aceitabilidade dos textos analisados, também a intencionalidade. Como o corpus da presente pesquisa abrange apenas a versão "definitiva" dos textos produzidos pelas crianças, sem versões preliminares nem registro de qualquer interação em que a intencionalidade fosse vislumbrada, não será possível discutir a informatividade nos moldes do trabalho de Rocha. Ela se apresentará sob a forma de inferências realizadas pelo leitor, suposições (muitas vezes especulativas) acerca do que o autor do texto queria dizer.

A inferenciação representa também procedimento essencial para (re)construção de sentidos no texto infantil no que diz respeito a dados cujas pistas lingüísticas são insuficientes para uma interpretação que se suponha pretendida pelo produtor do texto.

\section{Corpus e metodologia}

Para discutir essa questão, analisarei um texto produzido por uma criança que, de acordo com a avaliação da escola, tem "problemas de aprendizagem". Trata-se de um texto $0^{9}$ pertencente ao Projeto de Extensão "Diagnóstico e acompanhamento de casos de alfabetização", desenvolvido na UFPR e coordenado pela professora doutora Reny Gregolin, do Departamento de Lingüística daquela universidade. Tal projeto congrega crianças indicadas pela Escola Estadual Aline Pichett, de Curitiba, para serem atendidas por um grupo interdisciplinar composto por profissionais da neuropediatria, psicologia, lingüística, pedagogia e assistência social. Após passarem pelo atendimento médico, psicológico e assistencial, além de testes neurológicos e psicológicos, as crianças são acompanhadas por bolsistas em atividades de produção de escrita. Todo material produzido é arquivado e disponibilizado para o desenvolvimento de pesquisas na UFPR.

Julgo, de acordo com o paradigma indiciário proposto por Ginzburg (1986), que um episódio único na história de um sujeito, ou seja, jamais antes ocorrido e talvez nunca repetido, pode ser bastante significativo do processo por que passa tal sujeito em relação aquele dado aspecto. Não tenho a pretensão de, com as observações que farei a respeito de textos específicos, generalizá-las para todo e

8 op.cit.: 87

9 Texto gentilmente cedido por Josilene Brodzinski, mestranda $\mathrm{em}$ Lingüistica nesta Universidade. 
qualquer texto infantil. Um dos pressupostos básicos deste trabalho é a idiossincrasia que percorre o processo de aquisição da linguagem oral e escrita de cada criança. Portanto, as características que levantarei para o texto analisado a seguir restringem-se em última instância a ele. O que me parece geral a esse respeito é apenas que cada texto terá suas especificidades e que não há como procurar na produção escrita da criança indícios de passos que ela ainda não deu.

\title{
A geometria de um caso
}

\author{
Minha escola! \\ Minhae escola é chata por que tem uma menina camada Carolinia \\ muito chata e retardada e tem uma menina chamada Paula que \\ gosta de mim e esqueci de dizer que a Karolina é uma beseta de \\ toda as formás geométricas e idiota retardada, é uma chupa cabra \\ boboca, idiota, retardada, chupa cabra e quando ela crece ela vai \\ ser caminhoneira e ela usa aparelho. \\ ela e uma idiota \\ R L (3 $3^{a}$ série) $16 / 06 / 99$
}

A atividade que conduziu a esta produção foi a solicitação de um texto em que a criança escrevesse sobre sua escola, dizendo o que achava dela. Rogério aparentemente prefere falar de sua colega. Um professor mais "exigente" talvez dissesse que houve, se não fuga, pelo menos "desvio" do tema. Embora bem mais da metade do texto seja "dedicado" à Caroline, o título (Minha escola!) e a frase nominal com que a criança começa a escrever ("Minha escola é chata") indiciam uma tentativa de falar sim sobre a escola - ocorre que, neste texto, a amiga representa os sentimentos do narrador acerca do tema. Daí a opção pelo xingamento. O caminho percorrido pelo autor para escrever sobre o que lhe foi pedido é singular. Talvez não se esperasse de um adulto proficiente que, em um contexto como este, fizesse tais escolhas - não obstante tratar-se de escolha bastante criativa e reflexiva ${ }^{10}$.

10 Não pretendo com esta afirmação dizer que há consciência por parte da criança, mas tão somente dizer que a passagem em questão reflete um posicionamento em que percebo ausência de submissão aos padrões de pensamento e comportamento correntes. 
Outro aspecto relevante neste texto ${ }^{11}$ são as inadequações lingüísticas: pontuação (mau uso de vírgulas e pontos) e repetição de termos (chata, retardada, idiota, chupa cabra). Tais insuficiências precisariam ser trabalhadas pela escola, porém não na direção de uma mera "superação" dos "problemas". Entendo que a utilização que essa criança faz da pontuação e da repetição favorecem seu texto. Vejamos: se a intenção é produzir um xingamento, o efeito rítmico advindo da ausência de pontuação é no mínimo interessante. Para nada falar dos efeitos provocados pela reiteração. A ortografia por sua vez não interfere na interpretação que se pode fazer do texto.

Quero ainda chamar a atenção para a força retórica ${ }^{12}$ da expressão "besta de todas as formas geométricas", cuja construção se associa inevitavelmente à "besta quadrada", xingamento bem mais recorrente e portanto menos significativo do que a expressão criada por este aprendiz. Posso entender a partir dessa imagem que a colega (e por extensão a escola?!) não é somente uma besta quadrada, mas também redonda, oval, triangular, exagonal... portanto, é realmente muito chata essa seria a formulação própria de uma estrutura com caráter superlativo, cujo efeito de sentido é bastante eficaz. Posso atribuir a eficácia de tal passagem à reelaboração de uma metáfora cristalizada, que dá força estilística ao texto e ao fazê-lo "prende" o leitor, assegurando maior aceitabilidade e garantindo uma determinada construção de sentidos, quer seja intencional ou não.

\section{Conclusão}

Não posso afirmar, como Rocha (1999), que há insuficiência de informação no texto acima analisado. Alguns dos aspectos que o caracterizam são o uso de recursos coesivos recorrenciais, de uma estrutura frasal composta por coordenadas ligadas ou não por vírgulas e a criação de uma expressão nominal definida de caráter superlativo a partir de elementos conhecidos pelo produtor do texto e supostamente por seus leitores. Independentemente de chegarmos à idéia intencionada pelo produtor, (re)construímos sentidos para o texto a partir das ferramentas de que dispomos: as pistas nele presentes.

11 Meu interesse ao discutir esse texto não é esgotar suas possibilidades de sentido, mas apenas apontar alguns caminhos interpretativos possíveis para ele.

12 Agradeço a contribuição de Benito Rodriguez na reflexāo sobre esse trecho do texto. 
CAMPOS, C. M. A "Geometria" da construção...

As conseqüências disso para o ensino são a latente necessidade de ajudar os aprendizes a fazer suas escolhas - com tudo que esta palavra implica. E fazê-lo da única forma possivel: dando-lhes voz através de uma interlocução consistente.

\section{RESUMO}

Os textos produzidos por aprendizes são parte de um processo e têm, portanto, características próprias: é incoerente procurar neles a textualidade do adulto proficiente. Pelo contrário, podemos observar um uso peculiar e idiossincrático dos recursos disponíveis 'a criança' para a construção dos sentidos em seus textos.

Palavras-chave: Texto, sentidos, aprendizes.

\section{ABSTRACT}

Texts written by children are part of a process and have, therefore, their own properties: it is incoherent look for proficient adult's textuality at them. On the contrary, one can observe a peculiar and idiosyncratic use by children. They use the available means for building the meanings in their texts.

Key words: text, meaning, children.

\section{REFERÊNCIAS}

BEAUGRANDE, R.A. \& DRESSLER, W.U. Introduction to text linguistics. Londres: Longman, 1980.

CHAROLLES, M. Introdução aos problemas da coerência dos textos. In: ALVES, C.; ORLANDI, E.; OTONI, P. (Orgs.). O texto: leitura e escrita. Campinas: Pontes Editores, 1978.

FÁVERO, L.L. Coesão e coerência textuais. 3.ed. São Paulo: Ática, 1995.

FIGUEIRA, R.A. O erto como dado de eleição nos estudos de aquisição da linguagem. IN: CASTRO, M.F.P. (org.) O método e o dado no estudo da linguagem. Campinas: Unicamp, 1996.

GERALDI, J. W. Portos de passagem. São Paulo: Martins Fontes, 1991. 
CAMPOS, C. M. A "Geometria" da construção...

GINZBURG, C. Mitos, emblemas e sinais: morfologia e história. São Paulo: Companhia das Letras, 1986.

KOCH, I. V. A coesão textual. São Paulo: Contexto, 1990. O texto e a construção dos sentidos. São Paulo: Contexto, 1997.

KOCH, I. V. \& TRAVAGLIA, L.C. Texto e coerência. Petrópolis: Vozes, 1989. A coerência textual. São Paulo: Contexto, 1990.

ROCHA, G. A apropriação das habilidades textuais pela criança. Campinas: Papirus, 1999. 